\title{
STRUCTURAL ANALISYS OF CONCRETE PRE-STRESSED \\ RESERVOIRS FOR SLUDGE FERMENTATION - WATER WASTE TREATMENT PLANT BUCHAREST - GLINA. NUMERICAL FEM \\ ASSESSMENT OF THE STRUCTURAL RESPONSE FOR STATIC IN-DUTY LOADS
}

\author{
TUDOR BUGNARIU - Professor, PhD, Technical University of Civil Engineering Bucharest, Faculty of \\ Hydrotechnics. e-mail: bugnariu@utcb.ro
}

\begin{abstract}
The paper refers to a structural finite element analysis on the reservoirs for sludge fermentation subjected to static in-duty loads, at Glina Water Waste Treatment Plant. The purpose was to assess the stress and deformation states in subsequent erection and service conditions, to verify the design provisions and to emphasize the sensitivities, for a structure which was designed in the ' 80 s based on analytical procedures. The results obtained on the numerical models highlight the importance of the soil-structure interaction, in peculiar the one influenced by the soil mass deformability, on the overall structural response. Based on the calculated stresses, all structural components were verified according to the actual design codes at the ultimate limit state and the service limit state (water tightness/crack emergence).
\end{abstract}

Keywords: numerical modeling, pre-stressed concrete structure, soil-structure interaction

\section{Introduction}

The structural analysis is dedicated to the assessment of stress and deformation state of the reservoirs for sludge fermentation under standard in-duty load conditions. The goal of the analysis is to verify the way in which the design conditions are effectively fulfilled, in order to provide the strength capacity corresponding to the ultimate state limit (ULS) and the prescribed water tightness/crack opening limitation (SLS).

Main steps followed for the numerical approach:

- analysis of the design and execution documentation (project and subsequent documents, provided by the owner);

- development the numerical models for structure and foundation ground;

- calibration of the numerical models, based on the existing data;

- determination of structural response for each load case (hypothesis);

- post-processing and results interpretation, issuing conclusions and recommendations concerning further monitoring activities.

The FEM structural analysis is a verification tool available to emphasize how the conditions prescribed in the design process are fulfilled in order to provide structural safety and water tightness of the reservoir. The most important parameter is the stress level in the main structural components, i.e. to prevent/limit cracks emerging in the pre-stressed concrete.

Working hypotheses:

- The materials are considered homogenous and isotropic.

- The loading level keeps the structure material in a linear-elastic state (the loads are low enough to provide linear-elastic behavior).

The study includes verifications of the reinforced concrete cross sections (with passive reinforcements), based on the state of stress drawn out from the 3D analysis. 


\section{Structural Design Data}

The reservoirs for sludge fermentation are civil engineering structures made in reinforced prestressed concrete with post-tensioned reinforcement. The reservoir shape was designed to satisfy the technological requirements for the fermentation process as well the optimization of its structural behavior. The result is a special axial-symmetrical volume, made of thin plates with toroidal, tapered and cylindrical shapes. The internal geometry provides a satisfactory hydraulic spectrum for the sludge recirculation, an external surface close to minimum and an advantageous behavior for static and dynamic loads.

The foundation is made of a circular reinforced concrete circular slab with a diameter of $28 \mathrm{~m}$ and a thickness of $1.5 \mathrm{~m}$.

Inferior (lower) structural assembly - between local elevations \pm 0.00 and +12.00 :

- external cylindrical curved concrete plate (diaphragm wall), $0.45 \mathrm{~m}$ in thickness;

- internal cylindrical curved concrete plate (diaphragm wall), $0.35 \mathrm{~m}$ in thickness;

- tapered and toroidal curved concrete plates, pre-stressed along 2 directions (meridian and parallel), $0.65 \mathrm{~m}$ in thickness.

Superior (upper) structural assembly - between local elevations +12.00 and +36.00 :

- toroidal curved concrete plate, pre-stressed along 2 directions (meridian and parallel), $0.40 \mathrm{~m}$ in thickness; the maximal outside diameter is of $22 \mathrm{~m}$ and the minimal outside diameter is of $6 \mathrm{~m}$;

- circular reinforced cover plate, $15 \mathrm{~cm}$ in thickness, with technological holes.

The curved plates making the reservoir are provided with 4 ribs (local thickenings) on meridian direction, as supports for anchorages of the pre-stressed fascicles. They provide the alternation of the traction points.

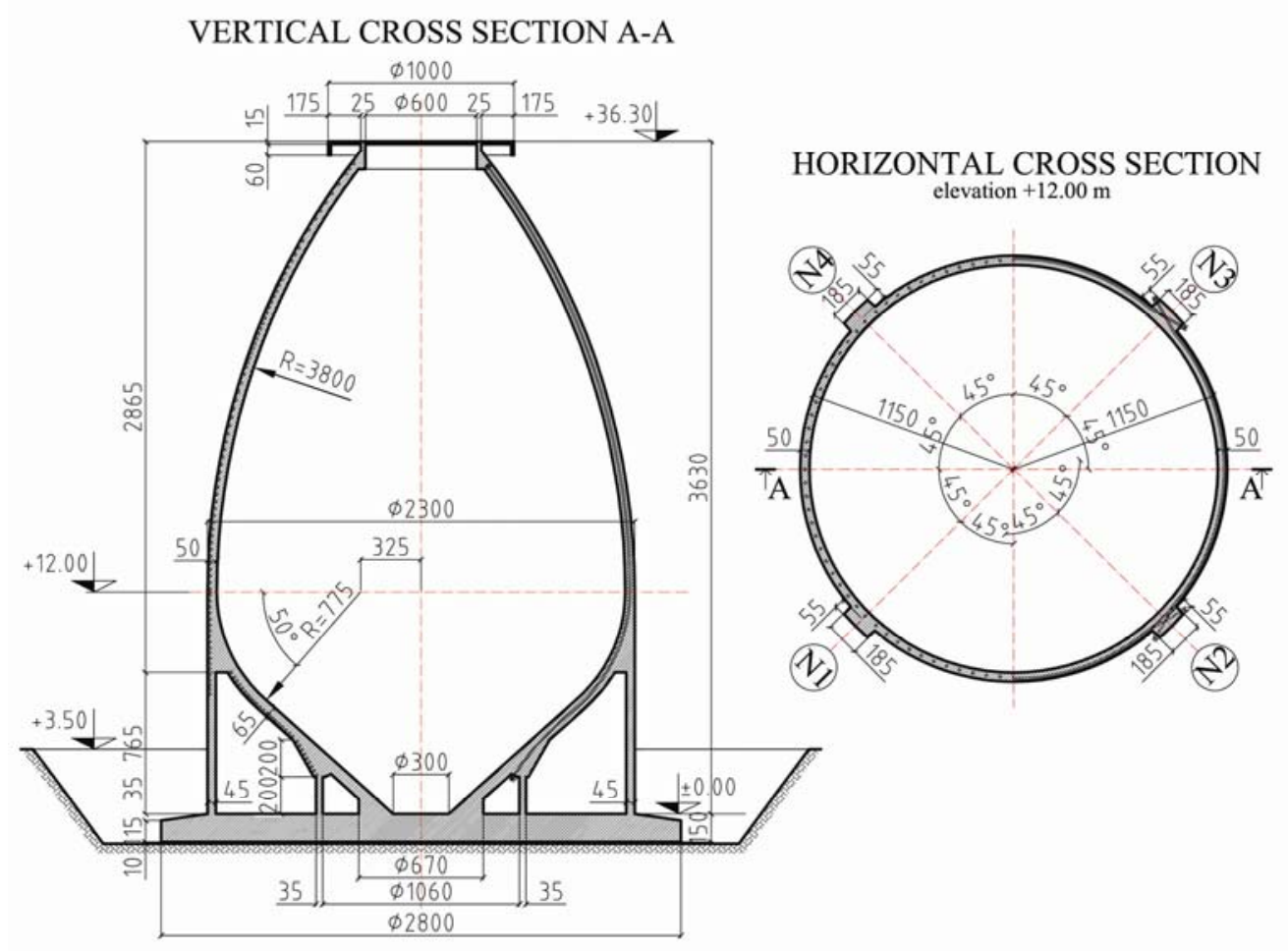

Fig. 1 - Structural components of the sludge fermentation reservoir

Pre-stressing is provided by high resistance $\varnothing 7 \mathrm{~mm}$ steel wire fascicles, along horizontal (ring/parallel) and meridian directions. 
The thermal insulation for the external surface is made of mineral wool mattresses covered with aluminum plates. The interior of the reservoir was initially protected with a plastered corrosion protection and lately with glass fiber membranes.

\section{Material Properties}

According to the design documentation, the concrete used for the reservoir is equivalent to the actual class C25/30, while the reinforcement is made of PC60 steel (passive reinforcement) and $\varnothing 7 \mathrm{~mm}$ STB I wires for the pre-stressing fascicles. Information concerning the geotechnical characteristics of ground are limited, but according to the design provisions, the foundation slab is placed over a $1.5 \mathrm{~m}$ thick sand and gravel layer, replacing the deformable natural clayey/dusty ground encountered down to the depth of $5 \mathrm{~m}$. Below this ballast pillow, the natural ground is made of sandy and sand and fine gravel layers with medium boulders, down to a depth of $18 \mathrm{~m}$. The ground water level was intercepted at a depth of $4.5 \mathrm{~m}$. According to the provided data, the natural ground is not prone to liquefaction at the reservoir site.

\section{Load Cases for Static Analyses}

The state of stress and deformation for the structure - foundation ground assembly was determined for several execution and loading stages, as well as those due to thermal field and wind pressure.

Mechanical actions (loads) - own weight, pre-stressing and internal pressure are grouped in the following load cases:

- Final execution stage, before pre-stressing (OW);

- Pre-stressing effect, empty reservoir (OW + PS);

- Reservoir filled-up at maximum level, elevation +35.30 m (OW + PS + HP).

Thermal field action - analyzed in the following hypotheses:

- Final execution stage, empty reservoir, warm and cold seasons;

- Full reservoir, on duty conditions in cold season;

- Full reservoir, on duty conditions in cold season with damaged thermal insulation.

Wind load - equivalent static pressure applied on the surface (according to the actual Romanian design code).

\section{The Finite Elements Models}

For the analysis purposes, two basic structural finite element models where developed:

- model SM1, in which the structure and the foundation ground are meshed in 3D finite element solids; it has the advantage to follow exactly the geometry of the structure and to be compatible with the thermal finite element model; results are expressed in stresses;

- model SM2, in which the structure is modeled using elastic shell elements with equivalent thickness, while the foundation ground is meshed in 3D finite element solids; bending moments, axial forces and shear forces are directly available, but the geometry and pre-stressing fascicles position are not so accurate; at the contact between structural shells, overlapping regions occur.

- model TM for the thermal field analysis. 
The mesh of the thermal model MT is identical with the structural one (except the foundation ground region which is missing), in order to provide the thermal field values in the same nodal points.

Some details of the first structural model SM1 are given below. It was built starting from the axisymetric geometry of the structure and the chosen limit of the foundation ground. The structural volumes defining the main components are meshed in 3D linear "brick" elements. A mapped mesh was always applied, providing at least 4 elements (with equidistant nodes) across the thickness of each plate. On vertical and angular directions, the mesh is delimited at intervals of about $0.50 \mathrm{~m}$ on the outer contour and the mid-height of the structure. Even if the elements shape ratio differs at the top and bottom of the structure, the difficulties of gradual meshing entailed this option. The boundary conditions and the coupling directions are oriented according to a cylindrical coordinate system. The model has 79264 elements with 98944 nodes corresponding to the structure and 34272 elements with 40159 nodes corresponding to the foundation mass. The axonometric view and the cross section of the finite element model are shown in figure 2 . Details of the mesh are represented in figure 3.
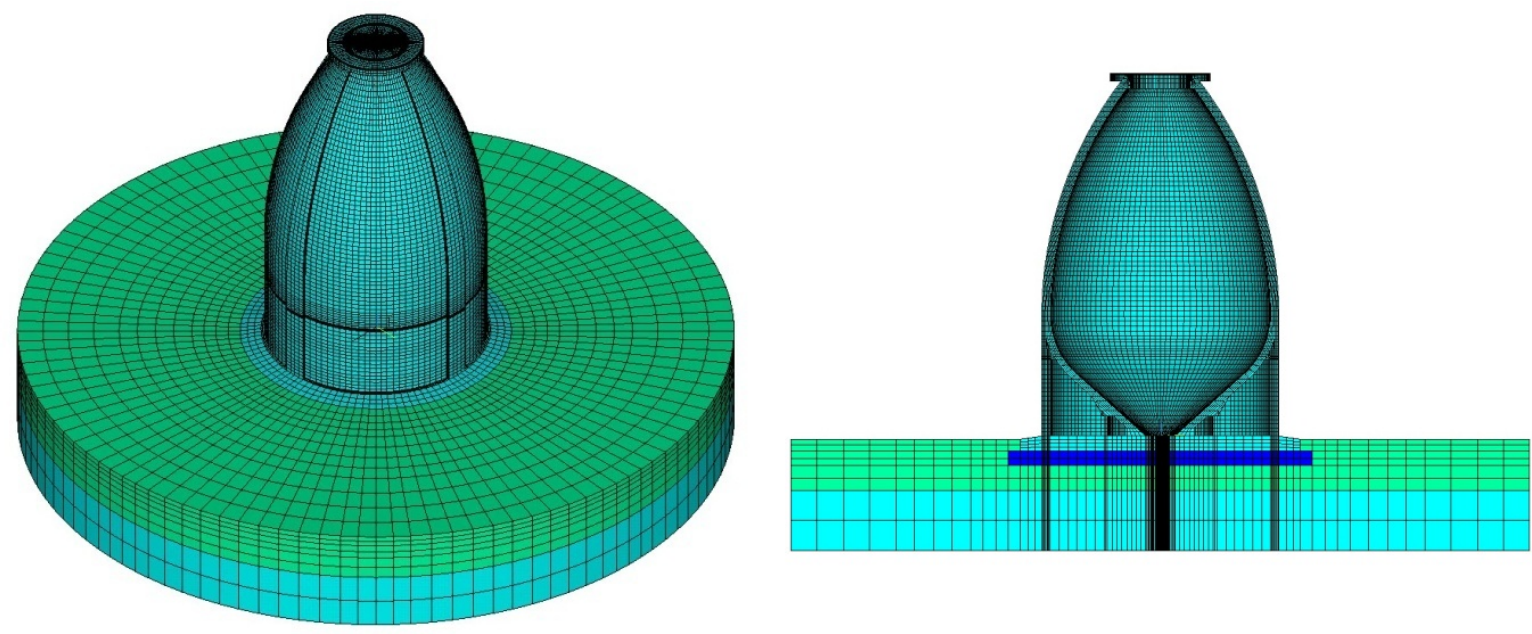

Fig. 2 - Axonometric view and vertical cross section of the model M1
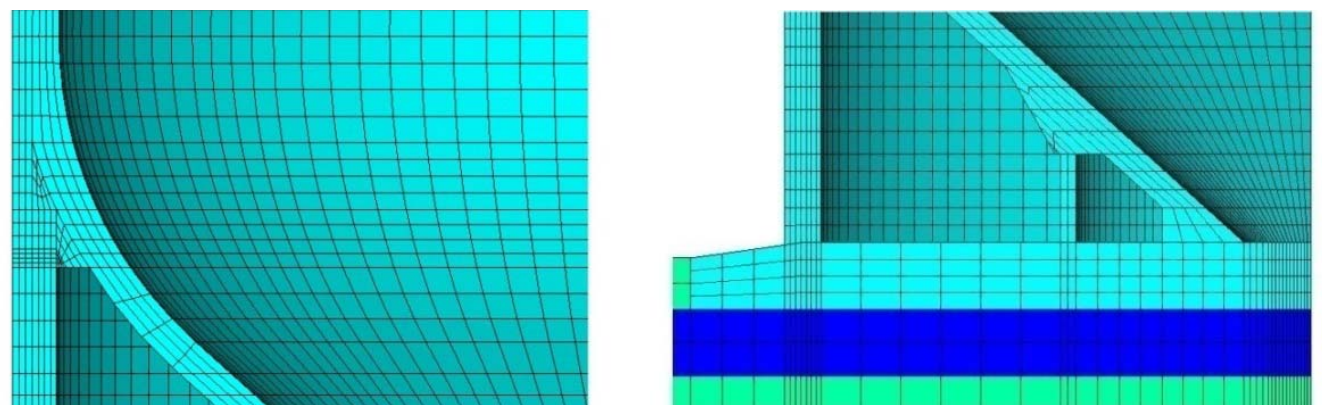

Fig. 3 - Meshing details for model M1

Along the modeling process, several supplementary finite element models were created in order to calibrate the parameters and for detailing the pre-stressing effect.

The pre-stressing system with fascicles of high resistance steel wires on two (ring/parallel and meridian) directions was modeled with separate linear spar 3D finite elements (with no bending stiffness), coupled in the nodal points of the mesh along the radial, tangential and meridian directions. The post-tensioning effect was modeled by assigning them an initial axial strain $\varepsilon_{a x, 0}$, corresponding to the local calculated stress values.

The traction forces and the initial pre-stressing level correspond to the provided design documentation. In absence of definite information concerning the pre-stressing tests and tension 
loss measurements, the loss of tension along the fascicles was assessed according to the design codes STAS 10107/90 and EN $1992-1-1$.

The modeling procedure for the pre-stressing effect implies the following steps:

- coupling the fascicles to the concrete structure mesh in positions corresponding as much as possible to the design provisions (as number and elevation);

- assigning the initial stress according to the calculated and averaged value of the residual pre-stressing effect, along the fascicles;

- assigning an equivalent cross section, due to the slightly different number of fascicles /intervals in the design provisions and in the finite element model.

A total number of 7884 spar elements with 8030 nodes are used for modeling the pre-stressing fascicles. A detail of horizontal fascicles modeling is shown in figure 4.

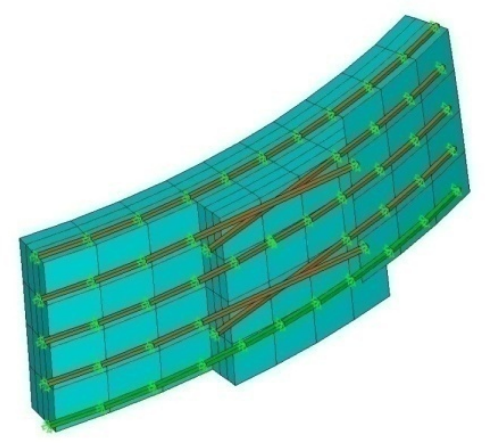

Fig. 4 - Detail of horizontal fascicles for model M1

\section{Assessment of Tension Loss in the Pre-stressed Fascicules}

The loss of stress was assessed according to the design code 10107/90 (in use in the design period) and verified with the European code EN 1992-1-1:2004. The components are:

$\Delta \sigma_{f} \quad-$ tension loss due to friction along the fascicule;

$\Delta \sigma_{\lambda} \quad$ - tension loss due to anchorage sliding;

$\Delta \sigma_{s} \quad$ - tension loss due to subsequent tensioning;

$\Delta \sigma_{\bar{\varphi}} \quad$ - tension loss due to concrete contraction and creep;

$\Delta \sigma_{r} \quad-$ tension loss due to reinforcement relaxation.

The loss of stress due to friction along the wire fascicle at a distance $s$ away from the traction point (position) is calculated with the following relation:

where

$$
\Delta \sigma_{f}=\left[1-e^{-\left(k s+\mu \sum \frac{L_{r}}{r}\right)}\right] \sigma_{p k}
$$

\footnotetext{
$\sigma_{p k} \quad$ - the axial control stress;

$s \quad$ - distance from the traction point, in meters;

$L_{r} \quad$ - length of each arc, in meters;

$r \quad$ - curvature radius, in meters;

$\mu \quad$ - friction coefficient along arc shape regions;

$k \quad-$ linear friction coefficient.
}

The friction coefficients $\mu$ and $k$ for post-tensioned reinforcements were taken from the design code (table 43, H.2.2) according to the channel type, the instance of wire fascicles insertion and the level of the characteristic force $N_{k}=A_{p} \sigma_{p k}>1300 \mathrm{KN}, \mu=0.24$ and $k=0.0012 / \mathrm{m}$ respectively. The stress loss due to local sliding in anchorages for post-tensioned reinforcements 
should be assessed with the friction coefficients $\mu^{\prime}=1.3 \mu$ and $k^{\prime}=1.3 k$ (according to H.2.4). The assessment is based on an iterative procedure, leading to the distance on which the local loss of stress is noticed and its actual value $\Delta \sigma_{\lambda}$.

In this particular case, the horizontal fascicles are arc shaped, spanning a $168^{\circ}$ angle, with straight lines at both ends, where simultaneous tractions are applied. The meridian oriented fascicles are made of three arches with different radii and an intermediate straight region corresponding to the lower tapered surface. Because the main parameter influencing the loss of stress for arc-shaped fascicules is the spanned angle (and not the arc length), the loss of stress was assessed conservatively for the fascicles with the maximum radius. Thus, the total loss of tension, due to friction and local sliding was calculated for prescribed regular intervals along the fascicles length, in tabular form.

The tension loss in the wired reinforcement due to the elastic deformation of concrete because of subsequent stressing of adjoins fascicles is calculated with the relation:

$$
\Delta \sigma_{s}=n_{p} \sigma_{b p, i+1, n} \text { with } n_{p}=\frac{E_{p}}{E_{b}}
$$

where $\sigma_{b p, i+1, n}$ is the axial compresion stress in concrete in the position of fascicle " $i$ ", due to stressing the other fascicles. Considering a relative influence of 6 adjoin fascicles, the mean value of the tension loss yields $200 \mathrm{daN} / \mathrm{cm}^{2}$ (for fascicles with the maximum cross section/number of wires, see table 1).

Table 1

Tension loss due to elastic deformation of concrete

\begin{tabular}{|c|c|c|c|}
\hline \multirow{2}{*}{$n$} & \multirow{2}{*}{$n_{p}$} & $\sigma_{b p}$ & $\Delta \sigma_{s}$ \\
\hline & & $\left(\mathrm{daN} / \mathrm{cm}^{2}\right)$ & $\left(\mathrm{daN} / \mathrm{cm}^{2}\right)$ \\
\hline 2 & \multirow{5}{*}{6.15} & \multirow{5}{*}{100.45} & 132.85 \\
\hline 3 & & & 177.13 \\
\hline 4 & & & 199.27 \\
\hline 5 & & & 212.55 \\
\hline 6 & & & 221.41 \\
\hline
\end{tabular}

The loss of stress due to relaxation for post-tensioned wires is

$$
\Delta \sigma_{r}=\Delta \sigma_{r \infty}\left(1-\frac{\Delta \sigma_{\bar{\varphi}}}{\sigma_{p o}}\right)
$$

with $\sigma_{p o}^{*}=\sigma_{p p}$ variable along the fascicle length (they depend on the friction loss of tension value). The mean value along the fascicle is $375 \mathrm{daN} / \mathrm{cm}^{2}$, with a maximum of $775 \mathrm{daN} / \mathrm{cm}^{2}$ at a distance of $7.5 \mathrm{~m}$ away from the traction point.

Finally, the loss of stress due to contraction and creep effects was calculated with the relation

$$
\Delta \sigma_{\bar{\varphi}}=n_{p} \sum \bar{\varphi}_{i} \sigma_{b p, i} K^{\prime}
$$

with $\sigma_{b p, i}$ the normal concrete stress under permanent load and $K^{\prime}$ a coefficient related to the passive reinforcement influence. According to the Annex $E$ of the design code, the maximum value of the characteristic deformation in time yields $\bar{\varphi}_{1}=2.7$ for the empty reservoir and $\bar{\varphi}_{2}=0.625$ for the reservoir in service conditions. The total loss of stress due to rheological reasons yields

$$
\Delta \sigma_{\bar{\varphi}}=\frac{E_{p}}{E_{b}}\left(\bar{\varphi}_{1} \sigma_{b p, 1}+\bar{\varphi}_{2} \sigma_{b p, 2}\right)=\frac{2000}{325}(2.7 \times 80+0.625 \times 10)=1367 \mathrm{daN} / \mathrm{cm}^{2}
$$


The graphs of stress distribution along the horizontal fascicles due to the total loss of stress is represented in figure 5 .

For modeling reasons, the continuous distribution of stress was replaced by discrete intervals of constant stress, easier to be assigned to the finite elements. The averaged distribution of stepped stresses is represented in figure 6.

Moreover, in order to simplify the entry data for the full extent analysis, a separate finite element model was created, to decide on the possibility to replace the variable tension stress along the horizontal fascicles with an average constant value. The idea is based on the fact that, according to the design requirements, each subsequent horizontal fascicle is rotated $90^{\circ}$ according to the adjoin ones. Thus, at subsequent levels placed at intervals of approximate $40 \mathrm{~cm}$, any radial cross section meets alternate high stressed and low stressed fascicles.

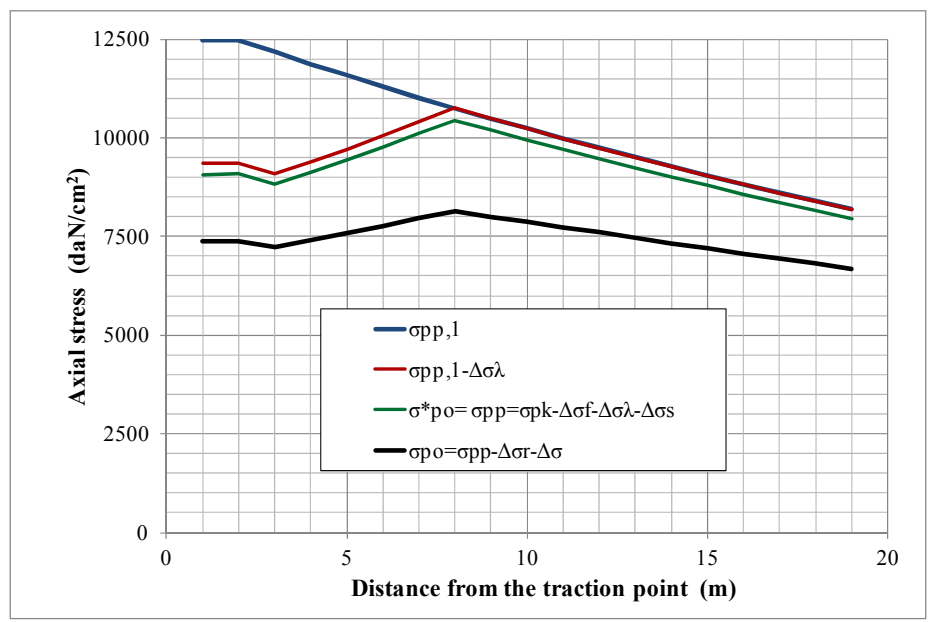

Fig. 5 - Axial stress distribution along the horizontal fascicles $\left(\mathrm{daN} / \mathrm{cm}^{2}\right)$

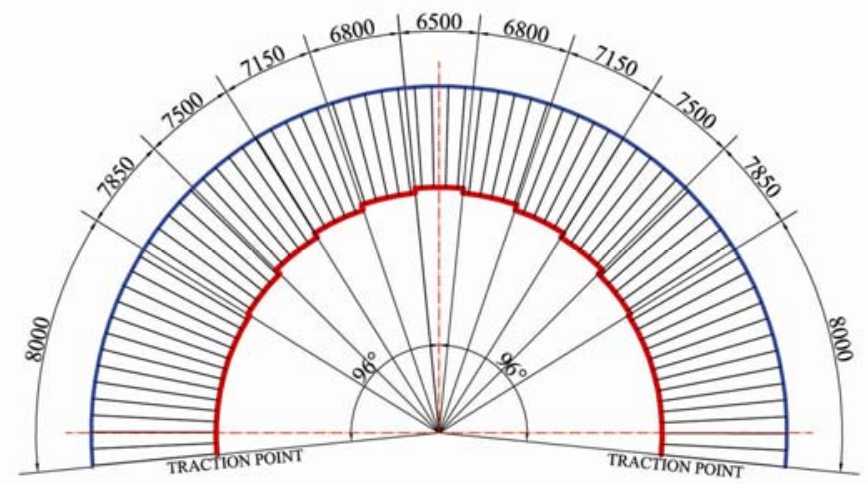

Fig. 6 - Discrete axial stress distribution along the horizontal fascicles $\left(\mathrm{daN} / \mathrm{cm}^{2}\right)$

The detailed analysis performed on an additional simplified model subjected to both variable and constant straining revealed that no significant differences are encountered from the point of view of stress interval values, deformation (displacements) or nodal forces. The result has enabled the simplification of the basic structural model regarding the assignment of the initial strain. Thus, the axial stress (initial stain) was considered constant for all spar elements used for modeling the horizontal fascicles.

Concerning the meridian-oriented fascicles, they are identical from the point of view of stress distribution. For each fascicle, the length is divided into regions with constant pre-stressing value, decreasing in steps from top (traction point) to bottom (fixing point). The loss of stress is assessed following the same rules explained before, taking into account the angle spanned by the curved (arc-shape) regions and the length of the fascicle. 


\section{Synthesis of the Analysis Results}

The main goal was to verify if the design requirements are fulfilled for the service limit state (SLS), mainly the requirements of water-tightness, by preventing cracking in the concrete mass. Cracking prevention is achieved if a general compression state of stress is induced in all components of the container. The peculiar type of structure and the character of its static load make this requisite more painstaking than the one corresponding to the ultimate limit state (ULS). The deformation trend was analyzed for all load cases, as well as the state of stress inside the concrete mass, considered as a homogeneous material. The results were completed with the verifications of the concrete sections with passive reinforcement.

In the framework of this paper, only a few graphical representations are selected to provide results and comments on the structure and its components, over subsequent load cases. More attention will be paid to the soil - structure interaction, considering that the analysis highlights some interesting aspects from this point of view.

\subsection{First Load Case - Own Weight}

The state of stress and deformation corresponds to the final stage of structural erection, before applying the pre-stressing (except the partial horizontal pre-stressing of the lower tapered plate, prescribed according to the project). All other elements modeling the pre-stressing fascicles are de-activated and the reservoir is empty. The result representations include the global settlement, the distribution of radial and vertical displacements, the vertical, horizontal and principal stresses. Some are shown in figures $7-10$. Most values corresponding to this load case are low enough to be disregarded in the framework of the analysis. The most stressed components are the foundation and the exterior cylindrical plate.

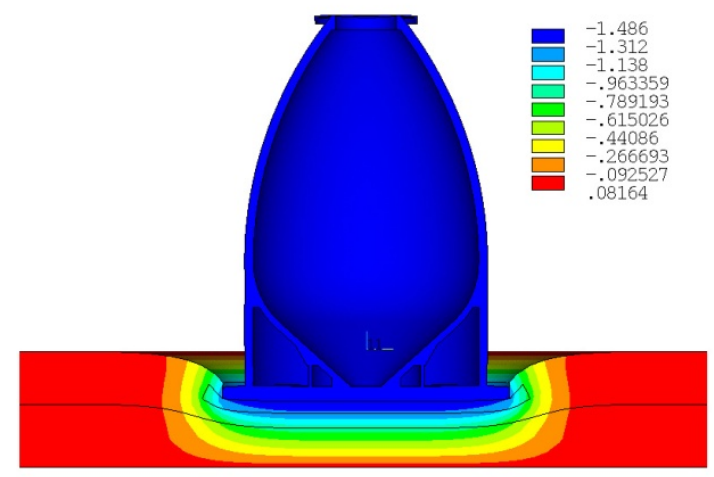

Fig. 7 - OW - Vertical displacements $u_{z}$ (cm)
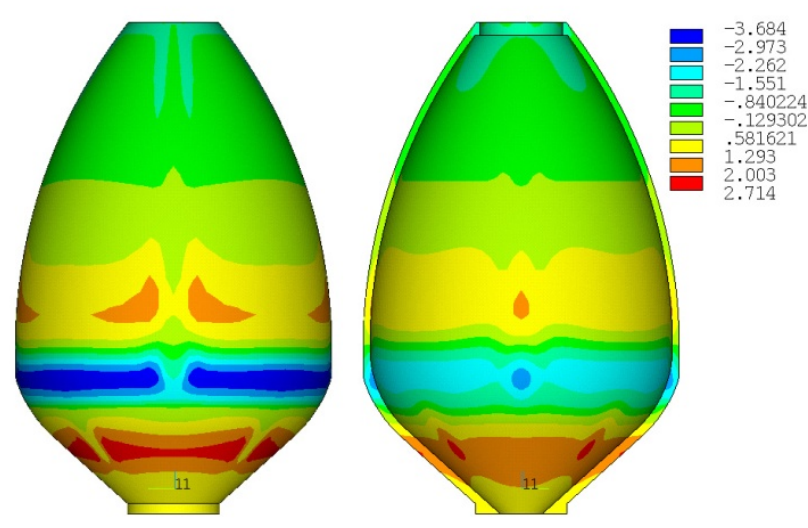

Fig. 9 - OW - Ring stresses $\sigma_{\theta}$ - outside and inside surface $\left(\mathrm{daN} / \mathrm{cm}^{2}\right)$
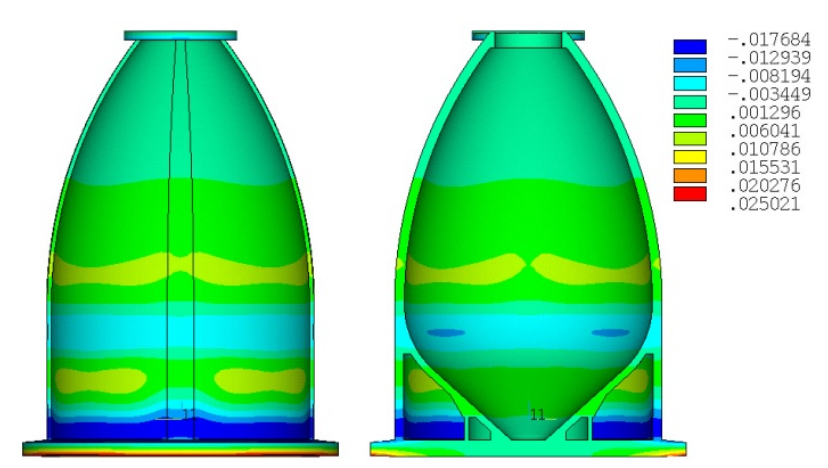

Fig. 8 - OW - Radial displacements $u_{r}$ - outside and inside surface $(\mathrm{cm})$
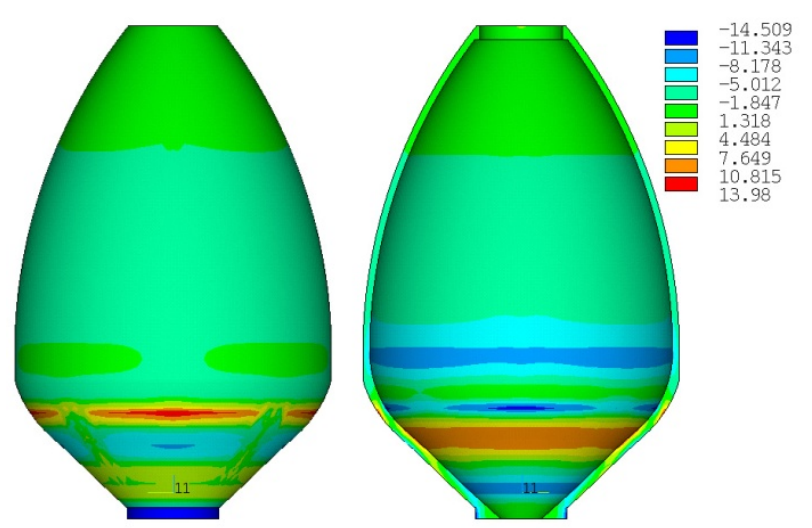

Fig. 10 - OW + partial pre-stressing - Vertical stresses $\sigma_{z}$ - outside and inside surface $\left(\mathrm{daN} / \mathrm{cm}^{2}\right)$ 
Some small tension stresses, susceptible to appear inside the lower tapered plate are due to the partial horizontal pre-stressing applied before erecting the structure above elevation +12.00 , are compensated during the filling-up procedure (proving the correctness of the design).

\subsection{Second Load Case - Own Weight and Pre-stressing}

The load case emphasizes the state of stress and deformation of the structure due to its own weight and complete pre-stressing, before filling-up the reservoir. The global settlement is comparable with the previous one, but the differential settlement between the center and the contour of the foundation shaft is accentuated. The general trend of deformation corresponds to a reduction of the radial dimension of the reservoir, due to pre-stressing, accompanied by the augmentation of compressive stresses on both horizontal and vertical directions. The results representations and comments include the global settlement, the distribution of radial and vertical displacements, the vertical, horizontal and principal stresses, as well as the axial stress along the horizontal and meridian fascicles. The maximal values of tension and compression stresses are encountered again at the bottom of the exterior cylindrical plate. This structural component is not part of the sludge container, therefore it should not fulfill water-tightness requirements. Spots of local high stress values are also present along the meridian stiffeners, concentrated at those nodes corresponding to fascicles connection. These local values represent an inadequacy of the model (a lack of local refinement), that can be neglected because they are also outside the main components of the container. Selected graphical representations of these results are shown in figures $11-16$. From the point of view of the stress state, it is obvious that this load case, due to the unbalanced compression effect of the pre-stressed fascicles along both directions, is the most significant one. The maximum compression stress in any direction is in the limits of the compression resistance of the prescribed class of concrete.
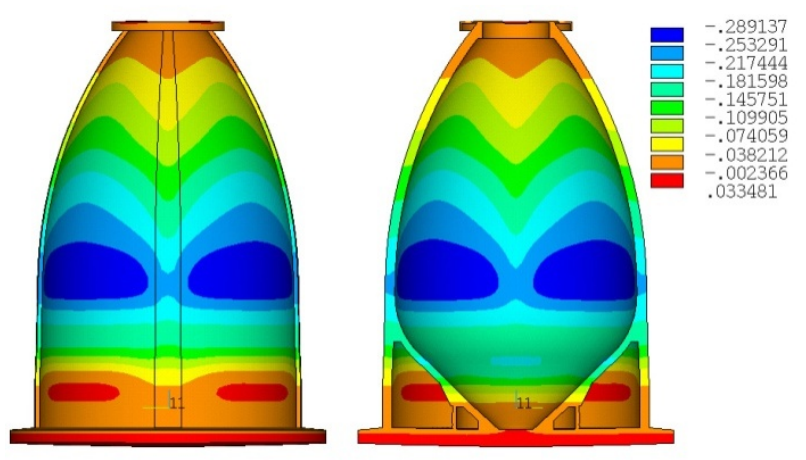

Fig. 11 - OW + PS - Radial displacements $u_{r}$ - outside and inside surface $(\mathrm{cm})$
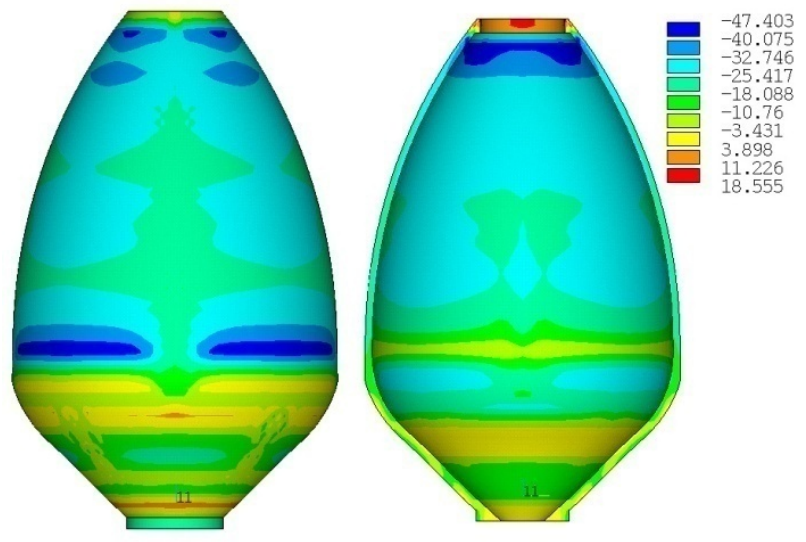

Fig. 13 - OW + PS - Vertical stresses $\sigma_{z}$ - outside and inside surface $\left(\mathrm{daN} / \mathrm{cm}^{2}\right)$
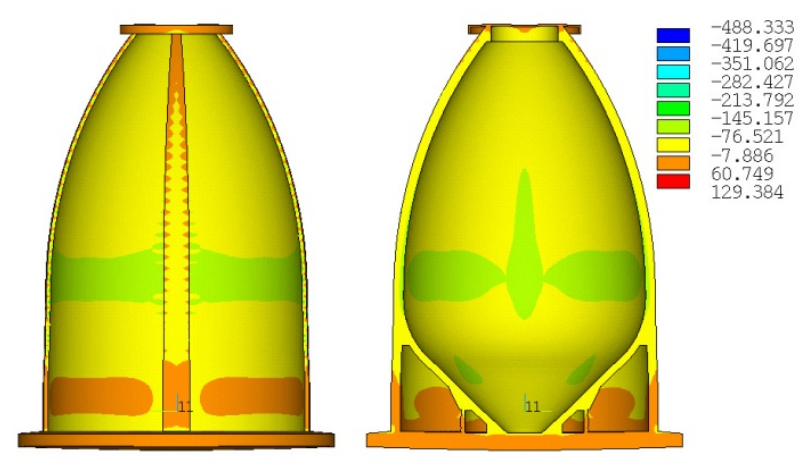

Fig. 12 - OW + PS - Ring stresses $\sigma_{\theta}$ - outside and inside surface $\left(\mathrm{daN} / \mathrm{cm}^{2}\right)$

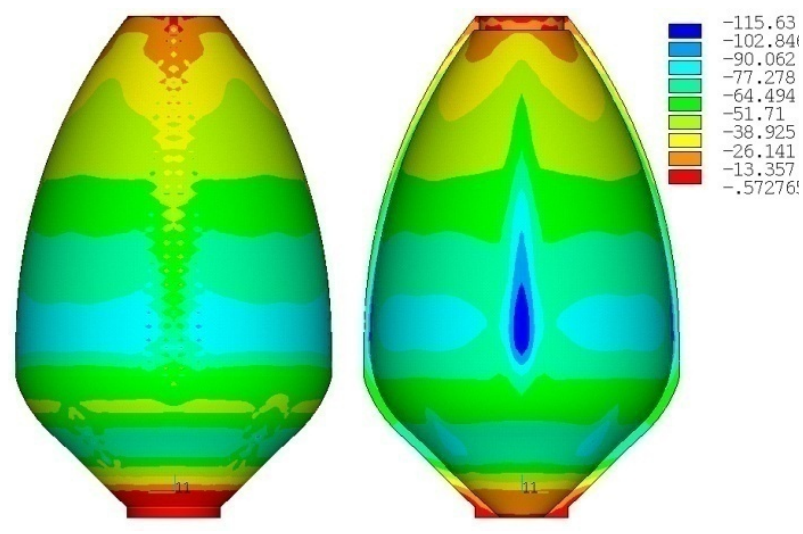

Fig. 14 - OW + PS - Ring stresses $\sigma_{\theta}$ - outside and inside surface $\left(\mathrm{daN} / \mathrm{cm}^{2}\right)$ 

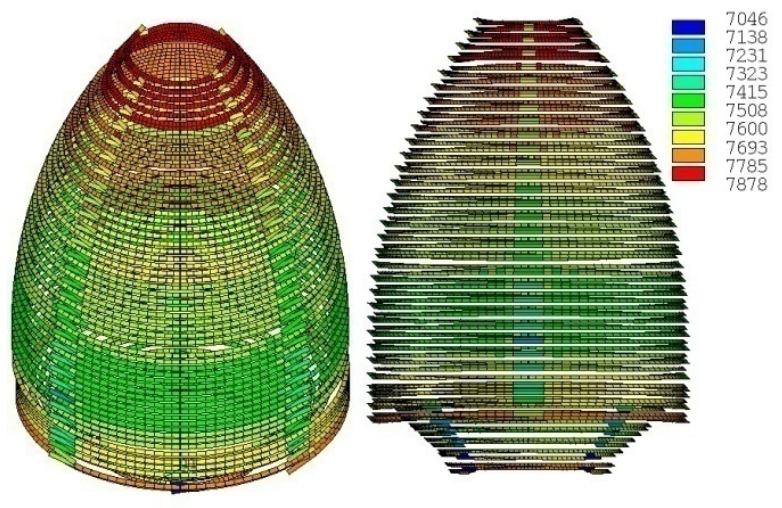

Fig. 15 - OW + PS - Axial stresses $\sigma_{a x l}$ - horizontal fascicles $\left(\mathrm{daN} / \mathrm{cm}^{2}\right)$
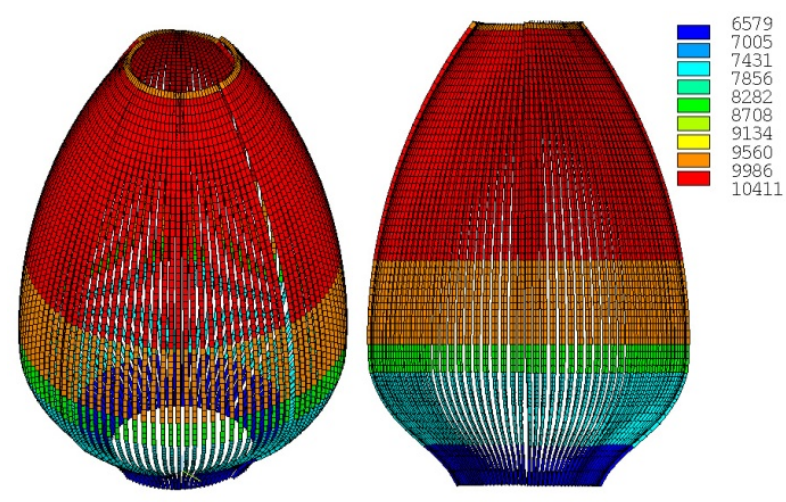

Fig. 16 - OW + PS - Axial stresses $\sigma_{a x l}-$ meridian fascicles $\left(\mathrm{daN} / \mathrm{cm}^{2}\right)$

\subsection{Third Load Case - Filling-up the Reservoir}

This load case determines the highest stress in all structural components as well as in the foundation ground. The mechanical actions applied on the structure are due to the own weight, the pre-stressing effect and the weight of the sludge, corresponding to the maximum service level $(+35.20 \mathrm{~m})$.

The filling-up effect was modeled as an internal pressure applied according to the sludge level and its specific weight. The pressure distribution shown in figure 17 is normal to the element faces and has a linear augmentation downward the vertical axis (a hydrostatic type growth).

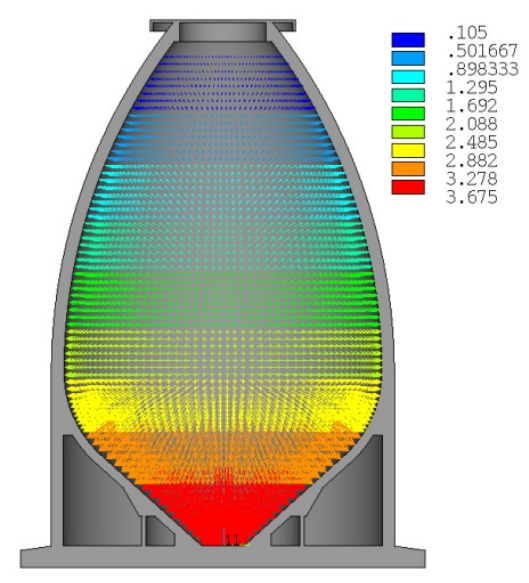

Fig. 17 - OW + PS + HP- Inside pressure distribution due to filling-up $\left(\mathrm{daN} / \mathrm{cm}^{2}\right)$

The deformed shape emphasizes the cumulative effect of the load combination, with a maximum settlement of $3.5 \mathrm{~cm}$, which duplicates the value of the previous load case. However, the foundation slab curvature is increased. An important finding refers to the radial displacements of the reservoir which still remain negative at all elevations, confirming the ultimate compressive state on the horizontal (angular) direction. The horizontal confinement stress in the container components yields between -5 and $-75 \mathrm{daN} / \mathrm{cm}^{2}$. Spots of local high stress values are present again on the lateral faces of the meridian stiffeners, but these concentrations can be disregarded as it was explained before. Some vertical tension stresses are present in the exterior cylindrical plate, but this component is not part of the restricted area and the stress level is well below the capacity of the provided reinforcement. Concerning the vertical stresses, they always remain in compression above the elevation $+12 \mathrm{~m}$ (the upper toroidal plates). Nevertheless, low vertical tension stresses are noticed on both faces of the lower toroidal and tapered plates, revealed also by the representations of the principal tension stress distribution $\sigma_{1}$. The position of the tension stresses concurs with the connection between these plates and the external cylindrical plate, developing a 
horizontal stiff ring. This observation determined an in-depth analysis in order to explain the circumstances in which the overall deformation of the structure is leading to these results.

The $3^{\text {rd }}$ load case leads also the highest stress values inside the foundation slab and at the bottom of the cylindrical plates. The corresponding bending moments and shear forces were used to verify the reinforcement of these components at the ultimate limit state (ULS).

Selected graphical representations of the results are shown in figures $18-22$.

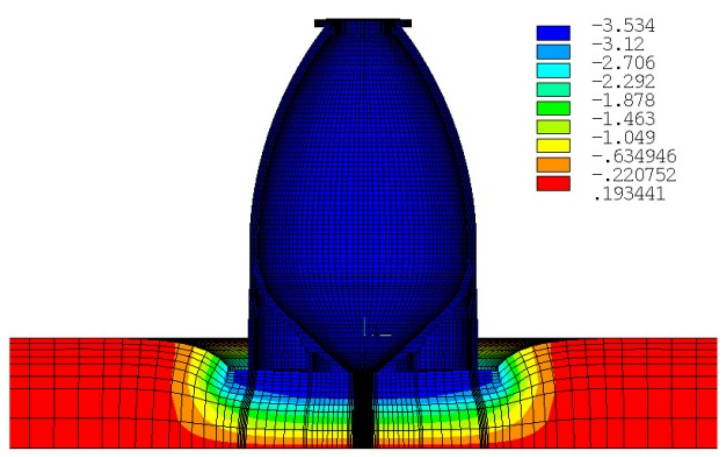

Fig. 18 - OW + PS + HP- Vertical displacements $u_{z}(\mathrm{~cm})$
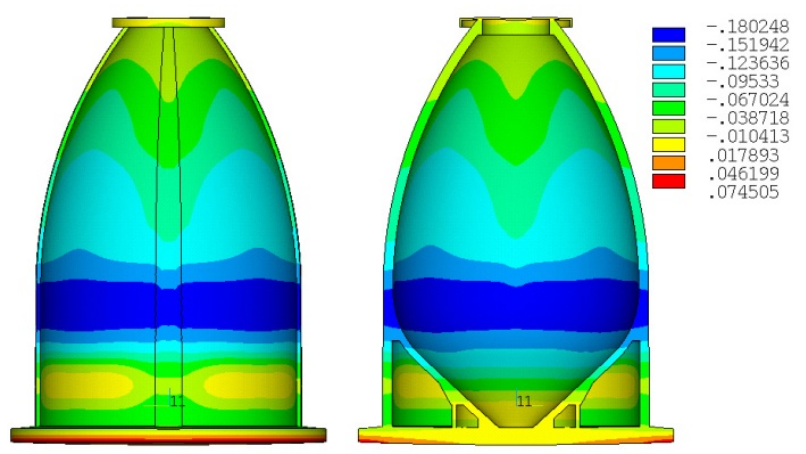

Fig. 19 - OW + PS + HP- Radial displacements $u_{r}-$ outside and inside surface $(\mathrm{cm})$
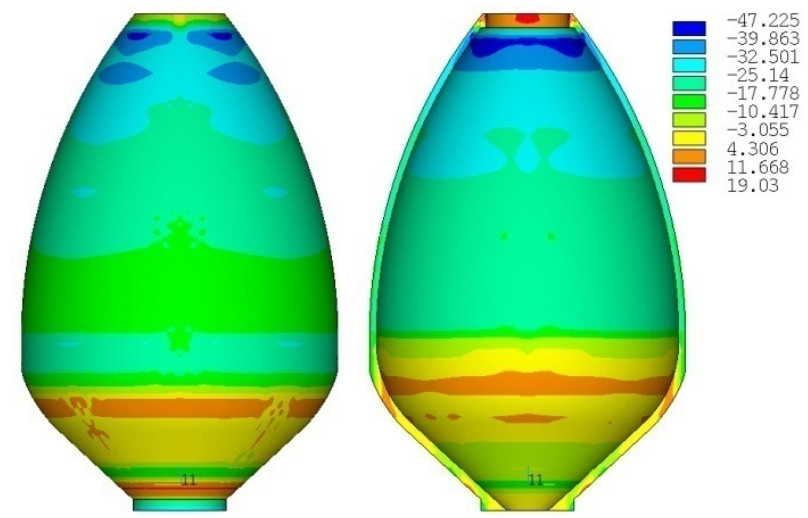

Fig. 21 - OW + PS + HP- Vertical stresses $\sigma_{z}$ - outside and inside surface $\left(\mathrm{daN} / \mathrm{cm}^{2}\right)$
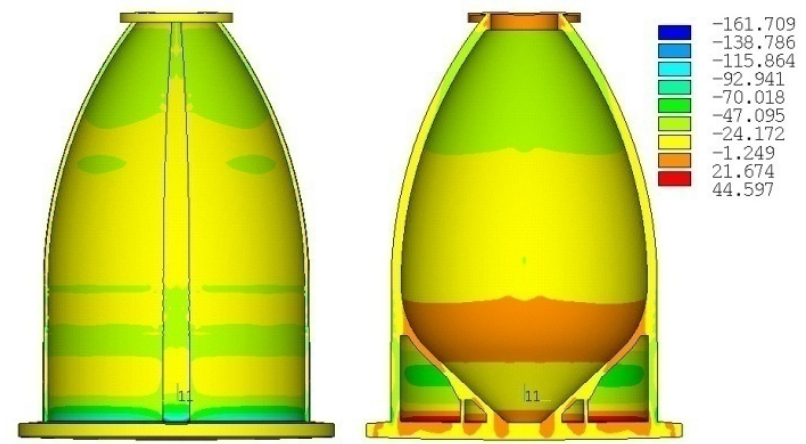

Fig. 20 - OW + PS + HP- Vertical stresses $\sigma_{z}$ - outside and inside surface $\left(\mathrm{daN} / \mathrm{cm}^{2}\right)$
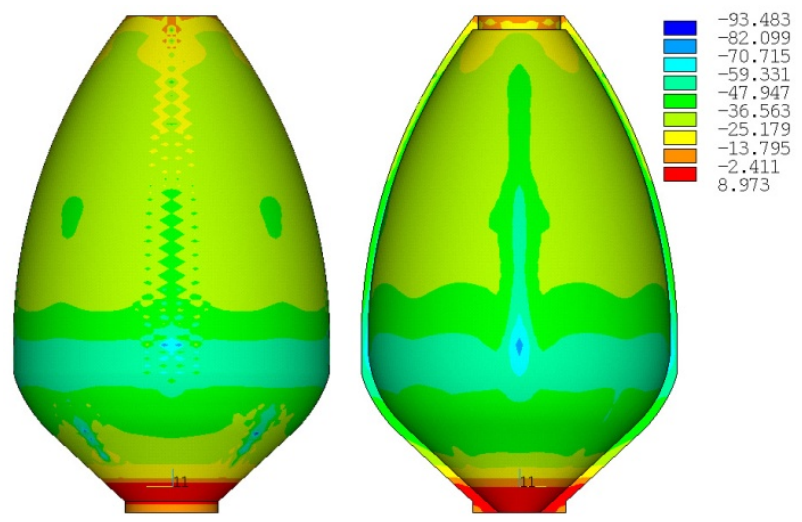

Fig. 22 - OW + PS + HP- Ring stresses $\sigma_{\theta}$ - outside and inside surface $\left(\mathrm{daN} / \mathrm{cm}^{2}\right)$

\subsection{Thermal Effects}

The induced state of stress due to constrained thermal deformations, associated to seasonal temperature variations, was assessed in two different circumstances: end of execution (empty reservoir, with no thermal insulation) in both summer and winter conditions, and in service state (filled-up reservoir, with external insulation) during the winter season. For all load cases, the 
nodal temperature distribution (the thermal field) is provided by thermal field analysis on models with an identical mesh. The thermal analyses are steady state ones, with boundary conditions applied on the external and the internal surfaces of the structure, as average constant values. The reference temperature was considered $7.5^{\circ} \mathrm{C}$, the extreme air temperatures $+35^{\circ} \mathrm{C} /-15^{\circ} \mathrm{C}$, the interior technological temperature $+35^{\circ} \mathrm{C}$ and the temperature on the bottom face of the foundation shaft $+10^{\circ} \mathrm{C} /+5^{\circ} \mathrm{C}$.

An example of temperature distribution (service conditions, winter) is shown in figure 23 . The corresponding state of stress and deformation due to the thermal field is represented on a selection of elements in figures 24 and 25. The interior temperature determines a structural expansion (positive radial displacements), inducing compression stresses on the inside face of the toroidal plates and tension stresses on the outside face. The stress values are moderate and favorable for keeping the water-tightness of the reservoir. Further analyses, with measured temperatures inside the bottom chambers in winter, confirmed the initial results.

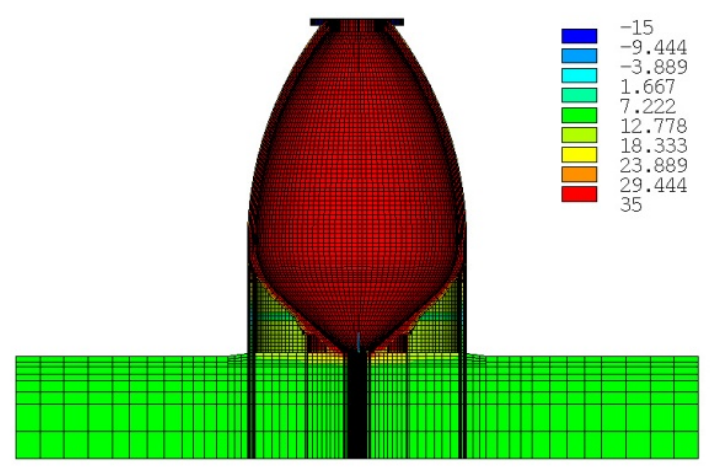

Fig. 23 - Thermal analysis- Nodal temperature distribution $\left({ }^{\circ} \mathrm{C}\right)$

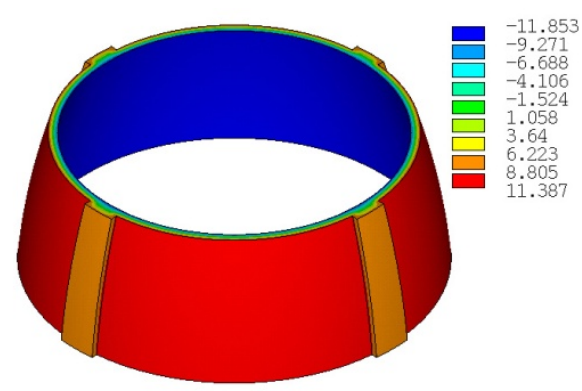

Fig. 24 - Thermal effects- Detail. Vertical stresses $\sigma_{z}\left(\mathrm{daN} / \mathrm{cm}^{2}\right)$

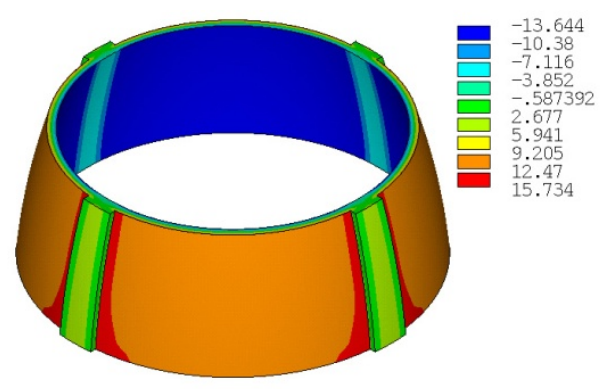

Fig. 25 - Thermal effects- Detail. Ring stresses $\sigma_{\theta}\left(\mathrm{daN} / \mathrm{cm}^{2}\right)$

\subsection{Wind Load}

The wind load was statically applied on the surface of the reservoir as a distributed pressure, assessed according to the design codes CR-1-1-4 and EN 1991-1-4-2006. This load, the only one which is not axi-symmetric, was considered an independent load case, to be added to any of the previous load cases. According to the site conditions, the reference dynamic pressure of the wind is $0.5 \mathrm{KPa}$. Compliant to the design codes, for most structures with the fundamental period lower than $1.0 \mathrm{sec}$, the resonant component of the dynamic pressure can be neglected, thus the wind load is considered static.

The external surface was divided into 160 discrete regions, each one with a constant assigned pressure. The wind load distribution is represented in figure 26.

The results of the analysis show a very low effect of the wind load. The structure is too stiff and too heavy to experience noticeable deformation, the small horizontal displacements $(4 \ldots 5 \mathrm{~mm}$ at the top) being the result of a slight overturning (rigid body motion) of the structure, due to 
ground deformability. The stresses induced by this load are 1 to 2 orders of magnitude lower than the ones due to the service conditions.

Thus, the analysis showed that this type of structure is insensitive to wind load. However, it should be mentioned that the steel frame sustaining the envelope and the envelope itself are not exempted to fulfill wind load requirements.

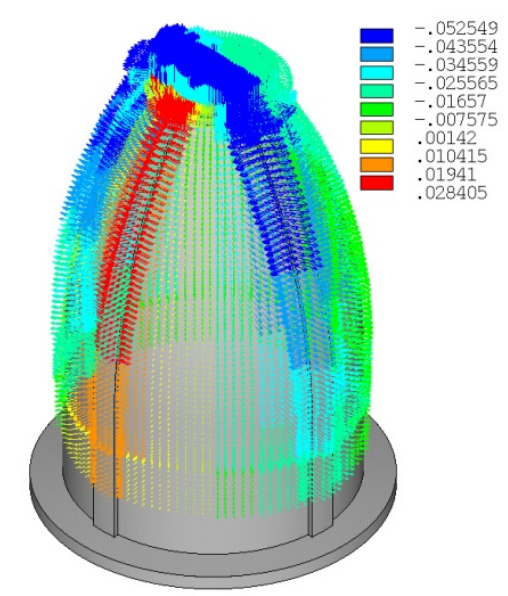

Fig. 26 - Wind load - Exterior pressure distribution $\left(\mathrm{daN} / \mathrm{cm}^{2}\right)$

\subsection{Stress and Deformation Evolution From One Load Case to Another}

Assuming a linear-elastic behavior, algebraic operations can emphasize the evolution between the load steps. The representation of relative values, as differences between subsequent load cases, was considered useful for explaining the results and for checking the accuracy of the model. The evolution of the deformed shape can be also analyzed as relative deformations, as shown in figure 27 (LC2 - LC1, the pre-stressing effect) or in figure 28 (LC3 - LC2, the reservoir filling-up effect).

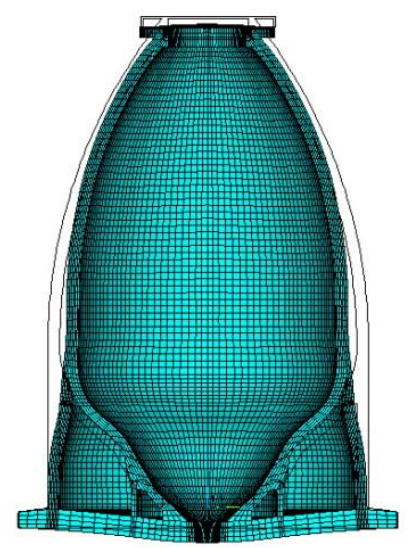

Fig. 27 - Pre-stressing effect - relative deformed shape load case 2 - load case 1 (PS)

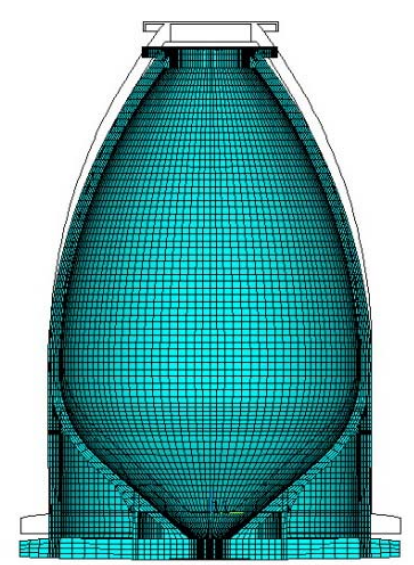

Fig. 28 - Filling-up effect - relative deformed shape load case 3 - load case 2 (HP)

\section{Significance of Interaction Between Structure and Soil}

The systematic turn-up of tensile stresses along the vertical (or meridian) direction in the lower toroidal and tapered plates entails a detailed analysis regarding the influence of the soil deformability. The detail of the deformed shape corresponding to the $3^{\text {rd }}$ load case (full reservoir) in figure 29 and the evolution of the absolute settlements in table 2 show a progressive bending of the foundation slab. The smaller vertical displacement of the slab contour, compared with its center, is not necessarily synchronized with lower contact stresses. The overall bending of the foundation slab is due to the concentration of gravity loads toward the axis, amplified by the 
confinement effect of the pre-stressed reinforcements. Hence, analyzing the displacement values, a hanging effect of the lower reservoir components on the exterior cylindrical plate is noticed. This effect induces the tensile stresses between the lower toroidal plate and the stiffer junction region at the elevation $+12 \mathrm{~m}$. The differential settlement of the shaft depends on the ground deformability. Thus, in order to assess the influence of the ground deformability on the stresses in the lower structural components, a parametric study was carried out, by increasing the elastic moduli assigned to the ground materials by 5,10 and 100 times (the last one corresponds to an almost undeformable ground). The results shown in table 3 (over a selected region of the lower plates) provide evidence that by augmenting the stiffness of the ground, the tensile stresses vanish. The justification of the tensile stresses by the spatial behavior of the ground - structure assembly is plausible, proving the advantages but also the limits of the model. The most important advantage stands for the indication of the sensitive regions of the structure. As main limit of the model, the linear elastic behavior should be mentioned, with no post-elastic redistribution capabilities. It is also important to mention that the presence of low tensile stresses does not necessarily mean the emergence of cracks in the concrete mass.

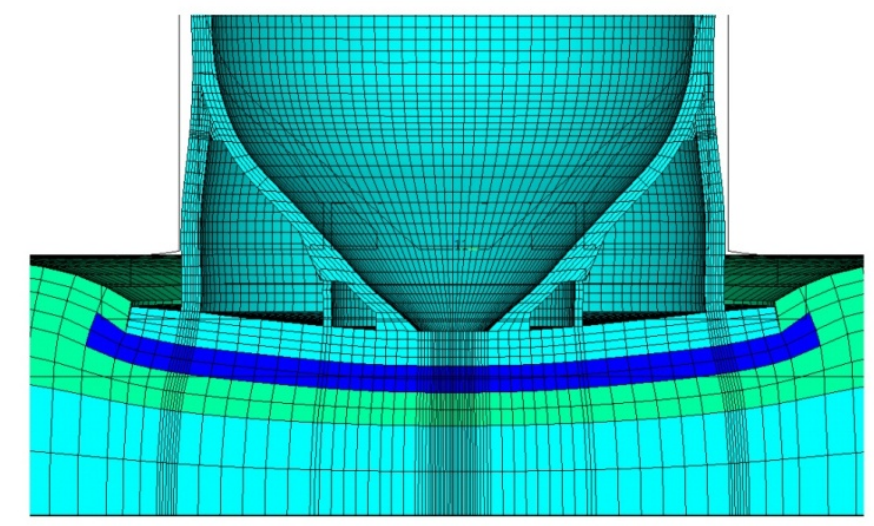

Fig. 29 - Detail of the deformed shape of the slab OW + PS + HP

Table 2

Vertical displacement values over load cases

\begin{tabular}{|l|c|c|c|}
\hline \multirow{2}{*}{\multicolumn{1}{|c|}{ Load case }} & \multicolumn{2}{|c|}{ Slab settlement $(\mathrm{cm})$} & \multirow{2}{*}{$\Delta f(\mathrm{~cm})$} \\
\cline { 2 - 3 } & Contour & Center & \\
\hline OW & 1.3793 & 1.4203 & 0.0409 \\
\hline OW+PS & 1.3893 & 1.5695 & 0.1802 \\
\hline OW+PS+HP & 3.2391 & 3.5137 & 0.2746 \\
\hline
\end{tabular}

Another illustration of the influence that the deformability of the soil mass has on the stress and deformation state of the structure is the way in which the gravity loads are distributed between the support components. These components are: the external cylindrical plate, with a radius of $11.10 \mathrm{~m}$, the internal cylindrical plate, with a radius of $5.80 \mathrm{~m}$, and the central massive ring with a diameter of $3.60 \mathrm{~m}$. The total weight of the structure and the contained sludge is differently distributed between these supports, according to the soil mass stiffness. The total reaction force at the base of each component is listed in table 4, for both deformable and perfect stiff grounds. The values represent the sum of vertical nodal forces at elevation \pm 0.00 , at the upper face of the foundation shaft. The relationship between the ground deformability and the distribution of the reaction forces is also represented as percentages in figure 30, for several values of the elastic moduli (2, 4 and 10 times the initially assigned value). If, for the perfect stiff ground, the total weigh is quite evenly distributed between the supports $(32 \%, 27 \%, 41 \%)$, for the initial ground material properties assigned for the analysis most of the weight $(83 \%)$ is distributed to the external cylindrical plate. 
Even if the total reaction force of each component is divided to the corresponding area of distribution (neglecting the shaft stiffness and weight), the foundation-ground contact pressure is significantly influenced by the soil deformability (as listed in table 5). The rather comparable values of pressure in case of deformable soil (below the external cylindrical plate and in the center of the foundation shaft), reveals the fact that the deformed shape of the structure actually complies with this smoothing of pressures.

Table 3

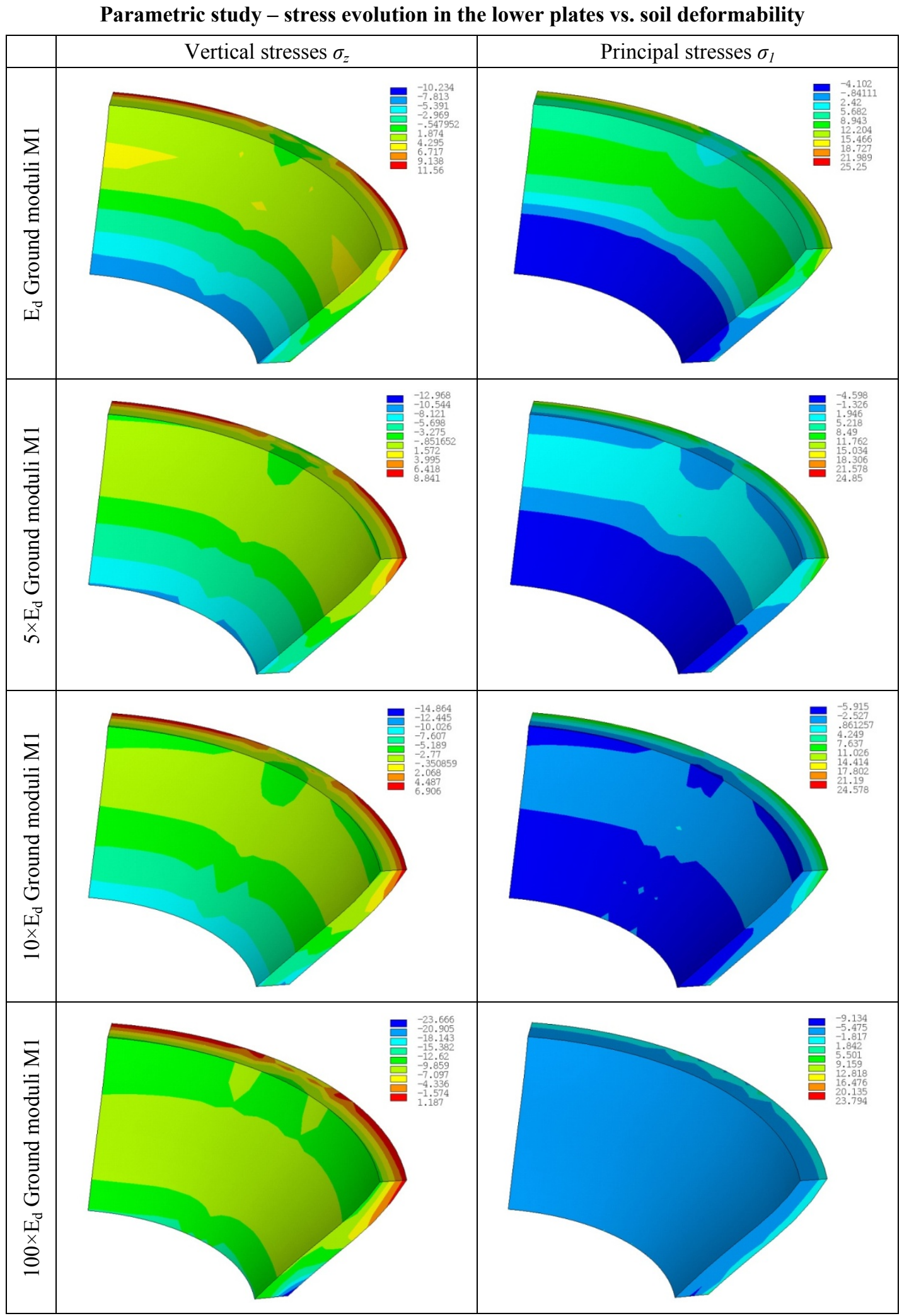


Distribution of the total vertical load toward the sustaining elements

\begin{tabular}{|c|l|c|c|c|c|}
\hline \multirow{2}{*}{\begin{tabular}{l}
\multirow{2}{*}{ STRUCTURAL } \\
ELEMENT
\end{tabular}} & \multicolumn{3}{|c|}{ TOTAL VERTICAL REACTION (KN) [\%] } \\
\cline { 2 - 5 } & \multicolumn{2}{|c|}{ STIFF GROUND } & \multicolumn{2}{c|}{ DEFORMABLE GROUND } \\
\hline 1 & Exterior cylindrical plate & 39643 & {$[32]$} & 103470 & {$[83]$} \\
\hline 2 & Interior cylindrical plate & 34042 & {$[27]$} & 9022 & {$[7]$} \\
\hline 3 & Central massive ring & 51250 & {$[41]$} & 12610 & {$[10]$} \\
\hline & TOTAL & 124935 & {$[100]$} & 125102 & {$[100]$} \\
\hline
\end{tabular}

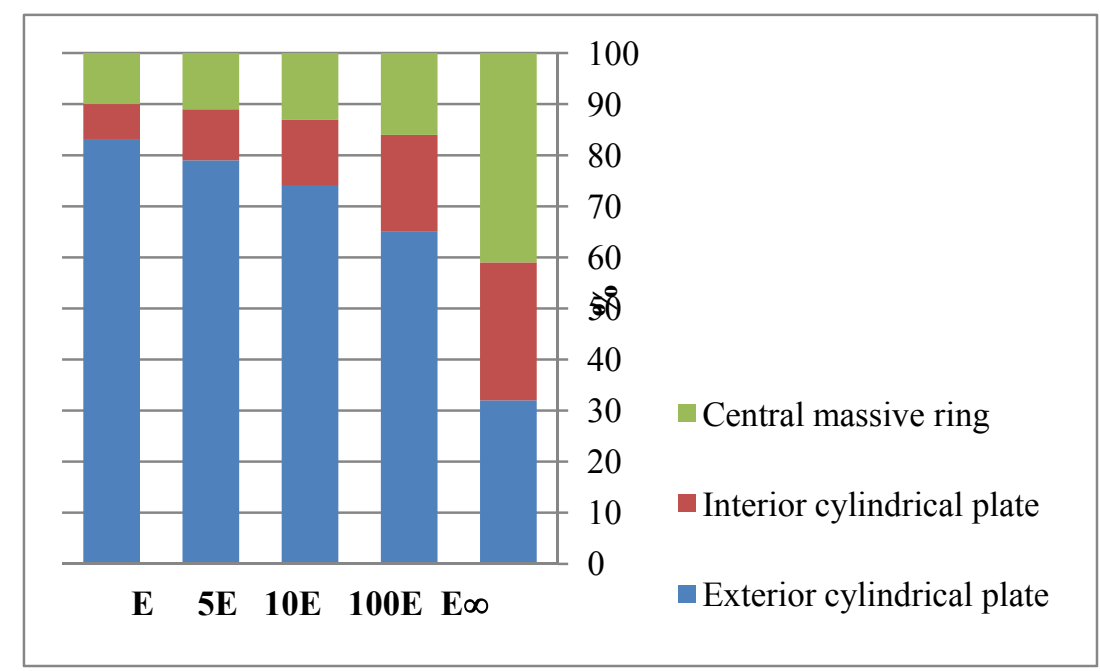

Fig. 30 - Percentage of total weight distribution on sustaining elements vs. soil deformability

Table 5

Distribution of the total vertical load toward the foundation ground

\begin{tabular}{|c|c|c|c|c|}
\hline & \multirow{2}{*}{ STRUCTURAL ELEMENT } & \multirow{2}{*}{$\begin{array}{l}\text { Afferent area } \\
\qquad\left(\mathrm{m}^{2}\right)\end{array}$} & \multicolumn{2}{|c|}{ AVERAGE GROUND PRESSURE $\left(\mathrm{KN} / \mathrm{m}^{2}\right)$} \\
\hline & & & STIFF GROUND & DEFORMABLE GROUND \\
\hline 1 & Exterior cylindrical plate & 396 & 100 & 261 \\
\hline 2 & Interior cylindrical plate & 160 & 213 & 56 \\
\hline \multirow[t]{2}{*}{3} & Central massive ring & 59 & 869 & 214 \\
\hline & TOTAL & 615 & 203 & 203 \\
\hline
\end{tabular}

\section{Concluding Remarks}

The design of the sludge reservoir fulfils the technological requirements and provides an adequate structural behavior. They have a peculiar axi-symmetrical shape, made of thin curved plates, with a minimal exterior surface for the designed capacity and with a advantageous behavior at static and dynamic loads. The design procedure was based on the analytical solutions for thin plate equations, introducing inherent simplifying procedures.

The structural analysis based on numerical modeling represents a verification on how the design provisions are effectively fulfilled, concerning the ultimate limit state and the water tightness requirements. The state of stress and deformation was assessed for subsequent erection and induty stages, as well as for various thermal field distributions and wind load.

The fine meshed 3D models follow in detail the geometry of the structure, including a reasonable region of the foundation ground. A lot of effort has been paid to modeling the pre-stressing effect of horizontal and meridian fascicles, by using elastic spar elements with initial staining. 
The concrete mass subjected to its own weight and pre-stressing is commonly characterized by principal compression stresses. The compression in all structural components yields significantly below the compression strength of the prescribed class of concrete. For in-duty conditions (filled-up reservoir), the highest level of stress is encountered in the components with passive reinforcements. Concerning the container, the state of stress and deformation is characterized by horizontal (ring/parallel) compressions all along its height. On meridian direction, the stress state is also compression above the elevation +12.00 , but tensile stresses can emerge in the lower plates, according to the ground deformability.

The seasonal temperature changes applied on the erected but empty structure are affecting only the lower supporting components of the reservoir, because of restricted displacements. The stress distribution over the container itself due to in-duty thermal field does not turn out conditions for interior cracks emergence or opening.

The wind effect analysis showed that, due to its significant mass and stiffness, the structure is not sensitive to such loads, only the insulation envelope being exposed.

All significant concrete cross sections provided with passive reinforcement were verified, proving that no structural component of the reservoir reaches its strength limit under in-duty load conditions. Concerning the service limit state, the required reinforcement conditions were checked for the lower toroidal and tapered plates along the meridian direction, where tensile stresses are susceptible to appear. It turned out that the design provisions are slightly uncovered from the rebar interspaces point of view. Anyhow, the water tightness requirement is no longer provided by an interior plaster (as the design provision was), the one being replaced by an interior glass-fiber membrane applied before the filling-up of the reservoir. In these circumstances, all structural components are protected as long as the integrity of the membrane is preserved and its deformability is larger than the structural stains.

Finally, the study revealed the importance of the soil - structure interaction, in peculiar the one influenced by the soil mass deformability. The recommendations include performing a new geotechnical study on site and applying precision surveying techniques during the oncoming technological activities of reservoir emptying/filling up. The expected data will improve the finite element model, by further calibration procedures.

\section{References}

[1] Institutul Român de Standardizare. (1990). Calculul şi alcătuirea elementelor structurale din beton, beton armat şi beton precomprimat. STAS 10107/0-90. Romania

[2] Asociația de Standardizare din Romania. (2006). Eurocod 2: Proiecarea structurilor din beton. Partea 1-1:

Reguli generale şi reguli pentru clădiri. SR EN 1992-1-1. Romania

[3] Asociația de Standardizare din Romania. (2008). Eurocod 2: Proiecarea structurilor din beton. Partea 3: Silozuri şi rezervoare. Anexa Naţională. SR EN 1992-3. Romania

[4] Asociația de Standardizare din Romania. (2006). Eurocod 1: Acțiuni asupra structurilor. Acțiuni generale Acțiuni ale vântului. SR EN 1991-1-4:2006 /AC:2010. Romania

[5] MDRT - UTCB. (2012). Cod de proiectare. Evaluarea acțiunii vântului asupra construcțiilor. CR 1-1-4/2012. Romania 